\title{
MATURAÇÃO E DISPERSÃO DE MICONIA CINNAMOMIFOLIA (DC.) NAUD. NA RESERVA BIOLÓGICA DE POÇO DAS ANTAS, MUNICÍPIO DE SILVA JARDIM, RJ, BRASIL.
}

\author{
Tânia Sampaio Pereira ${ }^{1}$ \\ Waldir Mantovani
}

Recebido em 11/05/00. Aceito em 25/07/01

\begin{abstract}
RESUMO - (Maturação e dispersão de Miconia cinnamomifolia (DC.) Naud.) Este trabalho avalia a maturação fisiológica de sementes de Miconia cinnamomifolia (DC.) Naud.- "jacatirão" sob o ponto de vista ecológico, ou seja, os processos de amadurecimento associados à dispersão. A quantificação da chuva de sementes ao longo da safra de dois anos consecutivos permitiu avaliar a produção de sementes da espécie para a região. Foi constatado que tanto os frutos verdes quanto os negros possuem sementes viáveis ao longo de toda a safra, que se estende por um período de 7-8 meses. A maturação ocorre de maneira irregular tanto na copa como em cada infrutescência. Colheitas quinzenais sobre matrizes marcadas observadas desde a fenologia floral até a maturidade dos frutos, revelaram uma intensa predação dos frutos negros. A maturidade fisiológica das sementes pode estar associada ao meio da safra, pois é quando o teor de umidade das sementes é mais reduzido e o percentual de germinação é mais alto. O percentual de germinação e o teor de umidade são bons índices de maturação; a coloração dos frutos não pode ser utilizada como índice de maturidade fisiológica, pois sementes provenientes de frutos verdoengos germinam tão bem quanto as de frutos negros. O percentual de maturação, ou seja, a relação de frutos verdes e negros sobre o número total de frutos demonstrou ser um bom índice de maturidade, embora possa ser mascarado pela intensa predação sobre os frutos maduros ao final da safra.
\end{abstract}

Palavras-chave - frutos, sementes, dispersão, germinação, Melastomataceae, Mata Atlântica

ABSTRACT - (Maturation and dispersal of Miconia cinnamomifolia (DC.) Naud.) This paper evaluates the physiological maturation of seeds of Miconia cinnamomifolia (DC.) Naud. - from an ecological point of view, i e., ripening processes associated to fruit dispersal. During two consecutive years seed rain samples were analysed and local seed production evaluated. Our results demonstrated that both green and black fruits have viable seeds during the whole harvest period (7-8 months). Fruit maturation is irregular in the canopy and in each inflorescence. Fortnightly harvests of target trees, observed from blooming to fruiting, reveal an intense predation of the black fruits. Seed physiological maturity could be associated to the middle of the harvest, when seed moisture is low and seed germination is high. Germination and seed moisture are good indicators of physiological maturation of this species; fruit color cannot be used as a good indicator, because both greenish and black fruits germinate equally well. Maturation percentage, i. e., the ratio of green and black to fruits totals proved to be a good indicator of maturity for Miconia cinnamomifolia, although the intense predation of black fruits at the end of the crop could obscure the results.

Key words - Physiological maturation, fruits, seeds, dispersal, germination, Melastomataceae, Atlantic Rain Forest

\footnotetext{
${ }^{1}$ Laboratório de Sementes, Instituto de Pesquisas Jardim Botânico do Rio de Janeiro, Rua Pacheco Leão, 915 - 22.460-030, RJ, Brasil, tpereira@jbrj.gov.br

${ }^{2}$ Departamento de Ecologia, Universidade de São Paulo, São Paulo, Brasil.
} 


\section{Introdução}

Uma das inúmeras perguntas que são feitas ao estudarmos uma espécie arbórea é: "como reproduzi-la?" Esta questão tem se tornado uma constante em nossos dias, quando mais e mais florestas são dizimadas, sem que tenhamos adquirido o conhecimento de como conservá-las. Conscientes deste problema, fazemos outra pergunta: "quando colher as sementes?"

Nos processos de maturação fisiológica as modificações do aspecto externo dos frutos são visíveis e podem ser acompanhadas até a completa maturidade, que pode estar associada ou não à deiscência ou abscisão dos mesmos. Após terem atingido o ponto de maturidade fisiológi$\mathrm{ca}$, as sementes tendem a se desligar da planta (Carvalho \& Nakagawa 1980) e sua permanência na árvore compromete a sua qualidade, pois corresponde a um armazenamento no campo, onde estão sujeitas às variáveis climáticas.

Determinações físicas e bioquímicas dos frutos e das sementes no decorrer da maturação podem indicar a maturidade ideal, quando devem ser colhidos os frutos visando a maximização da colheita, ou seja a obtenção de maiores percentuais de germinação.

De acordo com Popinigis (1985), o ponto de maturidade fisiológica das sementes é obtido quando as mesmas atingem o máximo de poder germinativo e vigor. Existem determinações adicionais, segundo Carvalho \& Nakagawa (1980), tais como peso, densidade, conteúdo de matéria seca, tamanho e teor de umidade, que indicam a maturidade das sementes. As determinações mais utilizadas têm sido o teor de umidade e o peso de matéria seca, sendo este último comprovado com sementes de soja por Marcos Filho (1979). Além destes, demonstramse como indicadores de maturação, a coloração e o aspecto morfológico dos frutos (Borges \& Borges, 1979), que é, sem dúvida, uma medida prática de avaliação, porém não tão precisa.

A maturação está intimamente ligada à dispersão; afirma Janzen (1983) que a maturação constitui um mecanismo de proteção dos frutos aos predadores indesejáveis, favorecendo assim os reais dispersores.

Em florestas tropicais os principais vetores de sementes são os vertebrados frugívoros Janzen (1983). Por esta razão, a frugivoria é um importante fator na organização da regeneração (Martinez-Ramos \& Soto-Castro 1993). A produção de frutos de uma determinada espécie tem que ser suficiente para saciar os predadores, permitir o consumo pelos reais dispersores e ainda formar um estoque de propágulos, seja sob a forma de banco de plântulas ou banco de sementes.

A questão a ser respondida por este trabalho é como saber, com o máximo de precisão, qual a melhor época de colheita dos frutos de Miconia cinnamomifolia, para se obter o máximo de germinação de sua safra de sementes e, assim, maximizar a sua colheita em bases ecológicas, ou seja, permitindo ao mesmo tempo o forrageamento da fauna e conseqüentemente, a dispersão, que irá colaborar com os processos de regeneração natural.

\section{Material e Métodos}

Seleção das matrizes arbóreas e acompanhamento da frutificação - Foram marcadas 12 matrizes adultas (diferentes daquelas utilizadas para a observação fenológica) de Miconia cinnamomifolia para acompanhamento da fenologia floral e da maturação fisiológica, ao longo da estrada para a Barragem de Juturnaíba no interior da Reserva Biológica de Poço das Antas, Município de Silva Jardim, Rio de Janeiro.

Devido à dificuldade de acesso à copa dos indivíduos adultos, foi construída uma torre ao lado de uma matriz adulta, que permitiu a observação e a manipulação das inflorescências, até a formação dos frutos. Desta matriz foram colhidos quinzenalmente ramos com frutos, que foram fixados em álcool $70 \%$, como referência das fases de maturação até o final da safra. Fo- 
ram ainda monitoradas, nesta matriz, 10 (dez) inflorescências desde o aparecimento dos botões até os frutos, registrando-se o número de botões, flores e frutos produzidos.

A fenologia floral foi acompanhada a partir da antese, ou seja, quando da abertura plena da maioria das flores de cada matriz, e estabelecido o período para a formação dos frutos, que ocorreu entre novembro e dezembro de 1995/ 1996.

Colheita dos frutos - A colheita dos frutos para análises da maturação fisiológica foi feita 30 dias após a antese, quando os frutos verdes jovens iniciaram a maturação propriamente dita, ou seja, assumiram o formato globoso, diferindo nesta fase do hipanto cupuliforme. Procedeuse ao sorteio quinzenal de seis árvores, dos 12 exemplares marcados para a colheita, de onde foram colhidos ramos com frutos de diferentes posições na copa. Cada colheita foi devidamente etiquetada, acondicionada em sacos plásticos e transportadas em caixa de isopor com gelo para o Laboratório de Sementes do Jardim Botânico do Rio de Janeiro.

Procurou-se processar os frutos no mesmo dia de sua colheita; quando não era possível, o acondicionamento acima foi prolongado no máximo até as primeiras horas do dia seguinte.

Protocolo de análises - No Laboratório procedeu-se à divisão do lote de frutos em quatro amostras de trabalho. Em 1/4 do lote efetuou-se a quantificação percentual das fases de maturação por colheita. Os testes para a determinação do teor de umidade de frutos e sementes, assim como os testes de germinação consumiram 2/4 do lote e o peso de 1000 frutos/sementes outro $1 / 4$ do lote.

Considerou-se uma sub-amostra de mistura com $6 \mathrm{~g}$ de frutos (em duas repetições de $3 \mathrm{~g}$ ) nas diferentes fases de amadurecimento, para a determinação do teor de umidade dos frutos, de onde foram também computados os valores quinzenais do peso fresco/seco dos frutos. O teor de umidade das sementes desta amostra foi feita com sementes de 20 (vinte) frutos, retiradas manualmente para duas repetições. A metodologia para determinação do teor de umidade segue as recomendações das "Regras de Análise de Sementes" (Brasil 1992), ou seja, secagem por 24 horas em estufa a $105^{\circ} \mathrm{C} \pm 3{ }^{\circ} \mathrm{C}$, procedendo-se à pesagem em balança de precisão, antes e depois da secagem.

Avaliação das amostras - Até o período de maturação final dos frutos de jacatirão, cada lote de sementes foi processado para germinação utilizando o seguinte procedimento: as sementes, após serem retiradas do fruto, sofreram uma lavagem superior a 6 horas em água corrente, a fim de lixiviar os inibidores de germinação presentes no fruto (Randi 1982). A viabilidade das sementes de cada amostra foi avaliada através de testes de germinação logo após a colheita. As sementes foram distribuídas sobre papel de filtro umedecido com água destilada, acondicionadas em caixas transparentes do tipo Gerbox. Os testes de germinação foram conduzidos em estufas encubadoras do tipo B.O.D. com temperatura constante de $25^{\circ} \mathrm{C}$ e de $30^{\circ} \mathrm{C}$ e fotoperíodo regulado para 8-16 horas/luz, com lâmpadas do tipo luz do dia. As contagens obedeceram uma observação a cada dois dias.

Foram conduzidos ensaios de germinação com sementes provenientes das safras de 1995 sob as temperaturas de $25^{\circ} \mathrm{C}$, e ainda sob $30^{\circ} \mathrm{C}$, pois a primeira temperatura apresentou repentina redução no percentual de germinação a partir da $9^{\circ}$ coleta. A temperatura utilizada para condução da germinação com a safra de 1996 foi então $30^{\circ} \mathrm{C}$ em decorrência dos resultados com a safra anterior.

Os parâmetros avaliados nos ensaios de germinação para as diferentes fases de maturação foram a germinação total (GT), que corresponde à emergência da radícula e germinação normal (GN), que corresponde à fase de plântula com todas as estruturas essenciais, em termos percentuais.

Produção via chuva de sementes - As sementes foram quantificadas através das análises da chuva de sementes. Foram adotadas pe- 
neiras coletoras confeccionadas em nylon e madeira não perecível, nas dimensões $0,50 \times 0,50 \mathrm{~m}$, afastadas do chão $(0,15 \mathrm{~m})$ num total de 30 peneiras, dispostas sob a copa de cinco indivíduos reprodutivos de jacatirão, em diferentes situações no gradiente de sucessão da Reserva. A disposição das seis peneiras sob a projeção da copa obedeceu à seguinte orientação em círculos: três peneiras eqüidistantes a $1 \mathrm{~m}$ do tronco (no meio da copa) e três eqüidistantes no limite da copa.

A cada quinze dias durante o período de duração da safra (7 meses para 1994 e 6 meses para 1995) o conteúdo de cada peneira foi coletado, individualizado por árvore e por peneira $\mathrm{e}$ acondicionado em sacos de papel etiquetados.

Os frutos foram contados manualmente e seu número foi registrado por peneira, divididos nas diferentes fases de maturação para o cálculo do percentual por fase. Os frutos de cada uma das 5 árvores, correspondentes a cada colheita quinzenal, foram então processados para germinação.

Adicionalmente, sem obedecer a uma metodologia, foram incluídas neste trabalho algumas informações referentes observações esporádicas sobre dispersão e forrageamento que constituem informações preliminares importantes à ecologia da espécie estudada.

\section{Resultados e discussão}

\section{Maturação fisiológica}

A época de produção de frutos é determinada por uma complexa mistura de fatores bióticos, tais como a abundância de dispersores e de fatores abióticos tais como a chuva (Levey 1990). As condições climáticas também influenciam diretamente a maturação dos frutos e sementes; Barnett (1979) afirma que as temperaturas baixas tendem a retardar a maturação. O início da frutificação do jacatirão pode ser detectado aos 30 dias contados a partir da antese, quando os frutos diminutos deixam de ter a forma cupuliforme do hipanto e assumem um formato globoso, semelhante ao do fruto maduro.

Num período de 60 dias observou-se uma ligeira modificação de tonalidade e de tamanho nos frutos a cada colheita quinzenal.

Aos 90 dias pode-se diferenciar quatro fases distintas na frutificação, que são os frutos verdes (FV), frutos verde-amarelados (FVAM), frutos verde-azulados (FVAZ) e os frutos negros (FN). Cada uma destas fases é acompanhada de um crescimento em tamanho, mas que, no entanto, não é diretamente proporcional à maturação, podendo-se encontrar frutos de diversos tamanhos em cada uma das fases citadas. Do meio para o final da safra foi registrada mais uma fase, os frutos secos (FS), estes podem pertencer a qualquer uma das fases anteriores. A análise quantitativa das fases dos frutos no decorrer da maturação foi feita em termos percentuais, com base no número de frutos em cada coleta para as safras de 1995 e 1996

(Figura 1). O teor de umidade tanto de frutos quanto de sementes variou em função do período da safra com destaque para a redução do teor de umidade no meio da safra. O peso de matéria seca tanto dos frutos como das sementes apresentou variação, porém sem obedecer a um pa-

\begin{tabular}{lcccc}
\hline & Botões & Flores & Frutos & $\begin{array}{c}\text { Q } \\
\text { amostras }\end{array}$ \\
\hline $\mathrm{N}$ & 2703 & 1686 & 772 & 10 \\
$\mathrm{n}$ & $270,3 \pm 83,02$ & $168,6 \pm 74,96$ & $77,2 \pm 40,82$ & \\
\hline
\end{tabular}

Tabela 1. Número (N) e média (n) \pm desvio padrão dos elementos reprodutivos de Miconia cinnamomifolia (DC.) Naud. quantificados durante a safra de 1995, na Reserva Biológica de Poço das Antas, RJ. 
Figura 1. Número percentual de frutos de Miconia cinnamomifolia (DC.) Naudin colhidos quinzenalmente por fase de amadurecimento durante as safras de 1995 e de 1996 na Reserva Biológica de Poço das Antas, IBAMA-RJ.

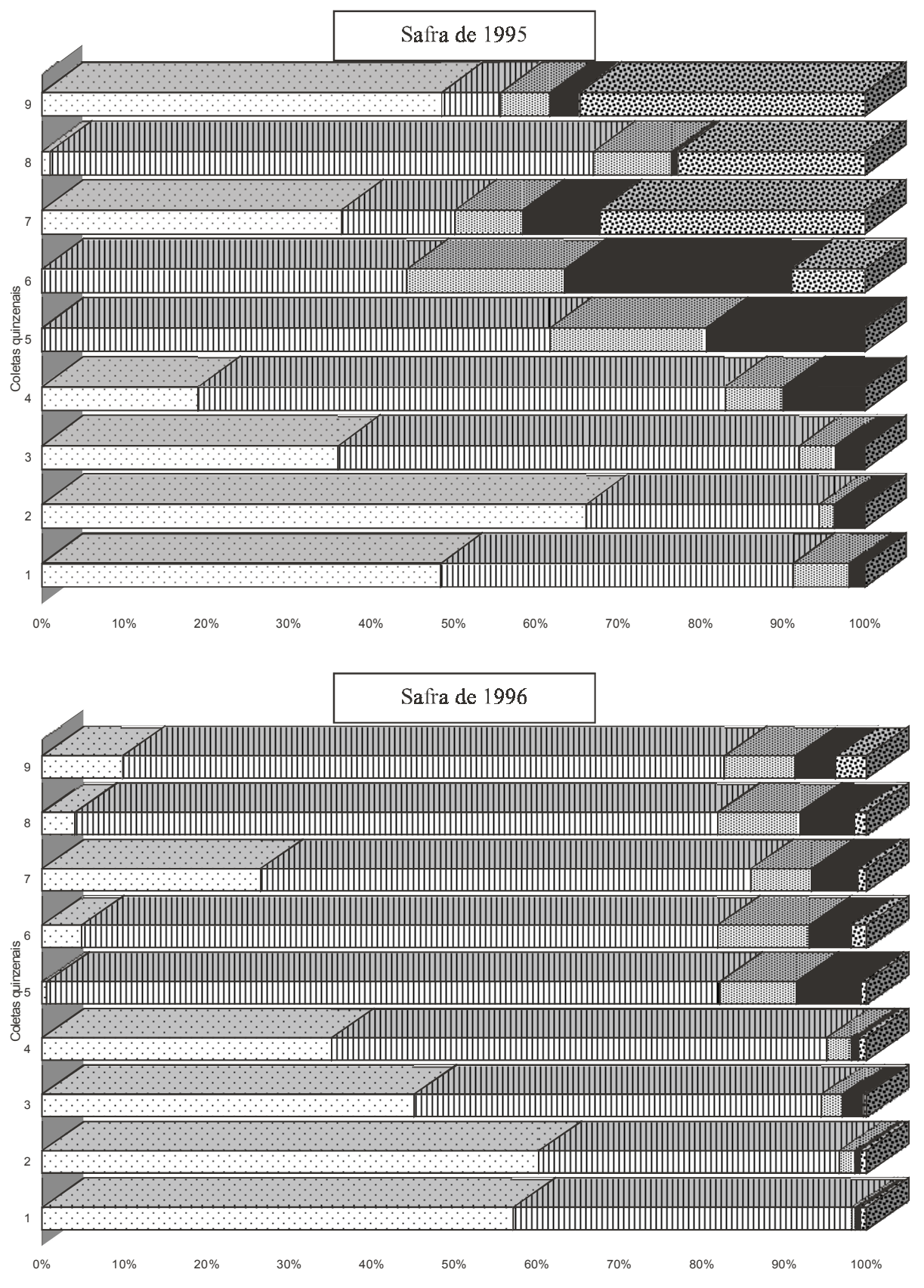




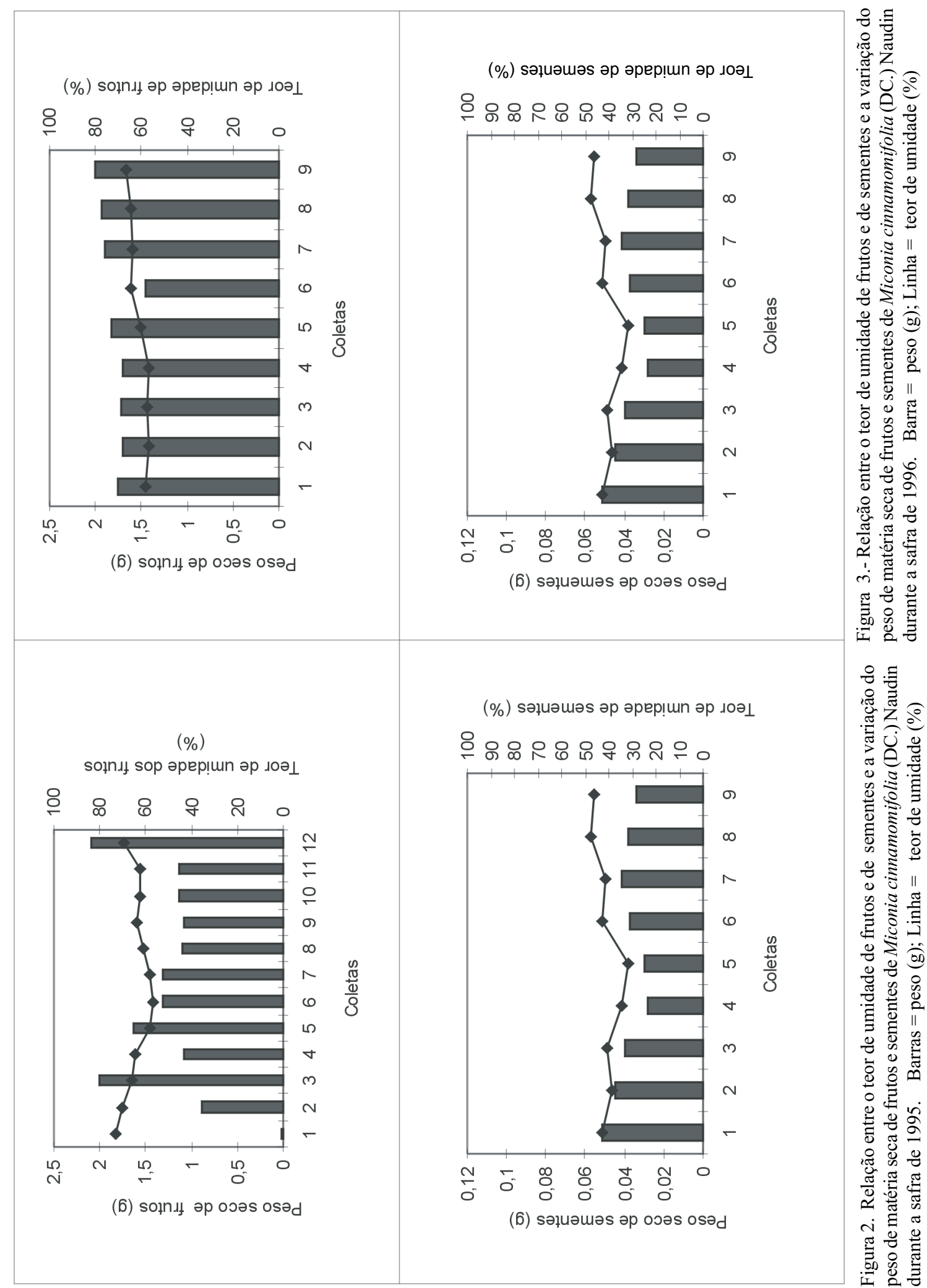


drão de um ano para outro. Os valores para frutos foram altos no início e no final da safra, sofrendo uma suave redução no meio da safra, enquanto que o peso seco das sementes apresentou uma flutuação maior com valores reduzidos no meio e no final da safra (Figura 2 e 3).

Segundo Lee (1990), as duas variáveis relacionadas à maturação dos frutos mais conhecidas são o tempo para a origem dos mesmos e a sua localização na planta ou na inflorescência, embora não se saiba a real importância de uma em relação à outra na alocação de nutrientes para a maturação dos frutos. $\mathrm{O}$ autor postula que os frutos são sugadores de recursos, competindo com os órgãos vegetativos por nutrientes, água e outros compostos e, por outro lado, os fitormônios produzidos pelos frutos e pelas sementes para o seu desenvolvimento teriam ação inibitória ao crescimento e ao desenvolvimento das unidades reprodutivas vizinhas.

Tabela 2. Médias de germinação ( \pm desvio padrão) de sementes de Miconia cinnamomifolia (DC.) Naud. provenientes de diferentes fases do fruto nas três épocas principais da safra em 1995 e 1996.

\begin{tabular}{|c|c|c|c|}
\hline \multicolumn{4}{|c|}{ Fases dos frutos do início da safra } \\
\hline \multirow[b]{2}{*}{ Temperatura } & 1995 & & 1996 \\
\hline & $25^{\circ} \mathrm{C}$ & $30^{\circ} \mathrm{C}$ & $30^{\circ} \mathrm{C}$ \\
\hline FN & $52,10 \pm 7,12 \mathrm{a}$ & - & $25,26 \pm 7,46 \mathrm{a}$ \\
\hline FS & $6,25 \mathrm{~b}$ & - & $6,25 \mathrm{~b}$ \\
\hline FV & $49,70 \pm 5,67$ a d & - & $6,25 \mathrm{~b}$ \\
\hline FVAM & $39,19 \pm 3,84 \mathrm{~b} \mathrm{c} \mathrm{d}$ & - & $6,25 \mathrm{~b}$ \\
\hline FVAZ & $57,74 \pm 7,16$ a & - & $27,11 \pm 4,21 \mathrm{a}$ \\
\hline \multicolumn{4}{|c|}{ Fases dos frutos do meio da safra } \\
\hline & 1995 & & 1996 \\
\hline Temperatura & $25^{\circ} \mathrm{C}$ & $30^{\circ} \mathrm{C}$ & $30^{\circ} \mathrm{C}$ \\
\hline FN & $41,49 \pm 6,07 \mathrm{a}$ & $52,61 \pm 4,90 \mathrm{a}$ & $54,58 \pm 7,98 \mathrm{a}$ \\
\hline FS & $31,17 \pm 10,79 \mathrm{a}$ & $35,86 \pm 9,11 b$ & $33,65 \pm 5,62 \mathrm{bc}$ \\
\hline FV & $44,91 \pm 8,91 \mathrm{a}$ & $54,67 \pm 8,64 \mathrm{a}$ & $43,20 \pm 10,75 \mathrm{a} \mathrm{c}$ \\
\hline FVAM & $41,50 \pm 6,85 a$ & $58,71 \pm 11,52 \mathrm{a}$ & $38,63 \pm 2,24 \mathrm{bc}$ \\
\hline FVAZ & $40,22 \pm 7,26 \mathrm{a}$ & $55,62 \pm 3,55 \mathrm{a}$ & $47,31 \pm 5,82 \mathrm{a} \mathrm{c}$ \\
\hline \multicolumn{4}{|c|}{ Fases dos frutos do final da safra } \\
\hline & 1995 & & 1996 \\
\hline Temperatura & $25^{\circ} \mathrm{C}$ & $30^{\circ} \mathrm{C}$ & $30^{\circ} \mathrm{C}$ \\
\hline FN & $36,69 \pm 7,92 \mathrm{a}$ & $42,13 \pm 1,15 \mathrm{a}$ & $23,29 \pm 9,36 \mathrm{a}$ \\
\hline FS & $51,99 \pm 4,06 \mathrm{~b}$ & $42,07 \pm 6,41 \mathrm{a}$ & $15,41 \pm 7,94 \mathrm{ab}$ \\
\hline FV & $38,03 \pm 3,06 \mathrm{a}$ & $33,05 \pm 5,27 \mathrm{a}$ & $8,89 \pm 3,05 \mathrm{~b}$ \\
\hline FVAM & $36,23 \pm 3,06 a$ & $35,38 \pm 8,32 \mathrm{a}$ & $17,56 \pm 6,95 \mathrm{ab}$ \\
\hline FVAZ & $38,53 \pm 7,00 \mathrm{a}$ & $42,68 \pm 4,44 \mathrm{a}$ & $26,30 \pm 5,44 \mathrm{a}$ \\
\hline
\end{tabular}

FN: frutos negros,FS: frutos secos,FV: frutos verdes,FVAM: frutos verde-amarelados,FVAZ: frutos verde-azulados

Médias seguidas pela mesma letra na coluna por época da safra não diferem estatisticamente entre si pelo teste de Tukey, ao nível de $5 \%$ de probabilidade. 
É grande a redução do número de botões para o de flores, e mais ainda para o número de frutos (Tabela 1), o que pode evidenciar a competição citada por Lee (1990); entretanto, tal redução não oferece prejuízos à safra de frutos, uma vez que a espécie é abundante na região, assim como a sua produção de frutos.

Miconia cinnamomifolia apresenta maturação muito heterogênea tanto na copa, quanto em cada infrutescência; são encontrados frutos em diversas fases de maturação, distribuídos de maneira desigual em cada ramo, obedecendo, no entanto, um padrão constante na copa de árvores na mesma fase de produção. Este padrão pode sugerir uma alocação parcial de nutrientes, que se distribui tanto na floração em pulsos, como na frutificação de maneira a suprir a planta em estádios, a medida que a mesma solicita recursos para finalizar os processos do desenvolvimento reprodutivo inicializados (botões florais ou desenvolvimento dos frutos.

Existe uma relação entre o percentual de germinação (GT\%) e o teor de umidade (U\%) nas diversas fases do fruto, em três épocas fixas da safra (início, meio e final) de 1996 (Figura
4).

A safra de sementes de 1995 foi superior em qualidade à de 1996, como pode ser observado na Figura 5, onde os valores de germinação total e normal, refletindo todas as épocas da safra de 1995, puderam ser registrados para quase todas as fases do amadurecimento, ao contário da safra de 1996, onde somente as sementes oriundas do meio da safra tiveram germinação e desenvolvimento de plântulas em todas as fases do amadurecimento.

Durante o processo de maturação ocorrem modificações bioquímicas, morfológicas e fisiológicas, que se iniciam com a fecundação do óvulo e cessam quando as sementes atingem sua máxima qualidade fisiológica, estádio este denominado ponto de maturidade fisiológica, por apresentar o máximo de poder germinativo e vigor para as sementes (Popinigis, 1985). Este ponto varia de espécie para espécie, e os indicadores visuais de maturidade dos frutos nem sempre correspondem ao máximo de valor germinativo das sementes. Este parece ser o padrão para os frutos de jacatirão.

$\mathrm{Na}$ Tabela 2 podem ser observados os valo-

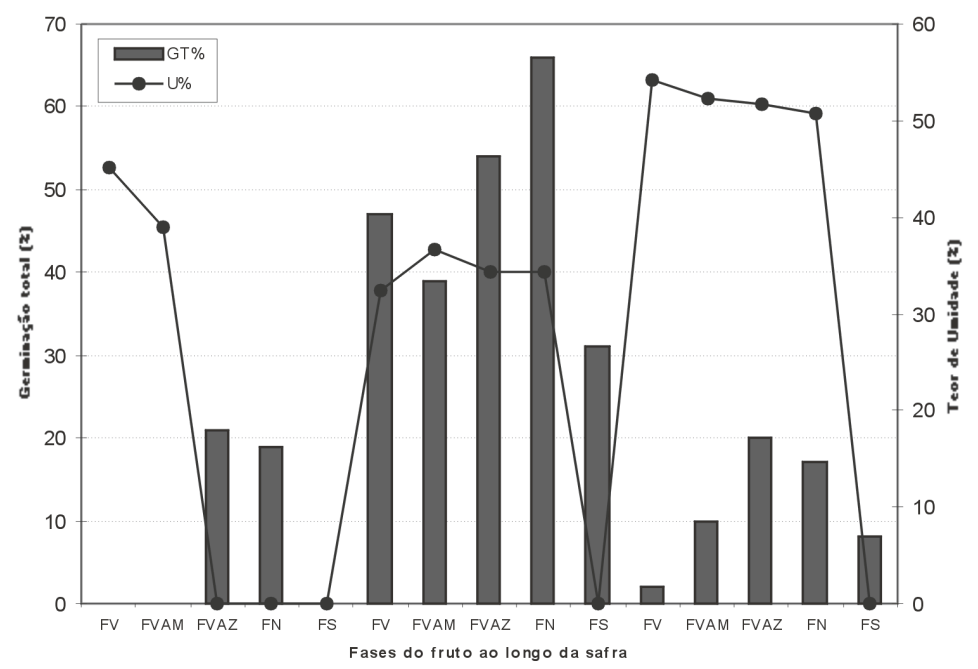

Figura 4. Relação entre o teor de umidade das sementes (\%) e a germinação total(\%) de Miconia cinnamomifolia (DC.) Naudin de diferentes fases de maturação ao longo da safra de 1996. ( FN: frutos negros, FS: frutos secos, FV: frutos verdes, FVAM: frutos verde-amarelados, FVAZ: frutos verde-azulados ) 
res da germinação associados à coloração dos frutos, onde o máximo valor germinativo das sementes está relacionado aos frutos verde-amarelados que, embora pareçam estar no início do desenvolvimento, aumentando em volume o pericarpo e conseqüentemente o teor de água, estão com suas sementes prontas para serem dispersas. Não há, entretanto, diferença significativa entre as demais fases, ao nível de 5\% de probabilidade através do teste de Tukey, à exceção dos frutos secos (FS). O percentual de maturação, ou seja, a relação de frutos verdes e maduros sobre o número total de frutos (Figura 1) demonstrou ser um bom índice de maturidade, embora possa ser mascarado pela intensa predação sobre os frutos negros $(\mathrm{FN})$ ao final da safra.

Queiroz (1983), em estudos preliminares de germinação utilizando sementes de Miconia cinnamomifolia provenientes de populações de Santa Catarina, constatou que tanto as sementes dos frutos maduros quanto as dos frutos verdes não apresentaram diferenças significativas nas porcentagens de germinação, podendo ser utilizadas indiscriminadamente, como pode ser também constatado através da Figura 5, em relação ao meio da safra com as populações de jacatirão da Reserva Biológica de Poço das Antas no Rio de Janeiro.

Figliolia (1993) ressalta que os índices de maturação visuais, bioquímicos, de tamanho, do peso de matéria seca, assim como o teor de umidade e a gravidade específica dos frutos e sementes permitem indicar o momento em que os mesmos devem ser colhidos. Em seu trabalho a autora constata que o tamanho, a coloração e o peso da matéria seca dos frutos, e a capacidade germinativa das sementes foram os principais índices de maturação dos frutos e sementes de Inga uruguensis.

Esta tendência no decorrer do processo de maturação é confirmada por Snow (1981), ao considerar que os frutos podem sofrer uma transformação abrupta, passando rapidamente do verde impalatável para o maduro palatável, com grande acúmulo de material nutritivo, que os tornam mais atrativos a seus agentes dispersores.

A medida que se processa a maturação, aumenta a atividade bioquímica, decorrente da produção enzimática no interior das células, proporcionando a síntese de substâncias orgânicas, responsáveis pelo crescimento e desenvolvimento da semente. Foi observado para Miconia cinnamomifolia que o percentual de germinação mais alto ocorre no meio da safra, quando o teor de umidade tanto de frutos como de sementes é mais baixo do que no início e no final da safra. Isto pode refletir o período de maturação fisiológica das sementes, ou seja, o melhor período para a colheita das sementes.

Tanto frutos como sementes, quando iniciam seu desenvolvimento, possuem alto teor de umidade, entre 70 e $80 \%$, que tende a decrescer com o desenvolvimento da semente, atingindo valor mínimo por ocasião da sua maturidade fisiológica (Popinigis, 1985; Carvalho \& Nakagawa, 1980). Neste estádio estabelece-se o equilíbrio entre o teor de umidade e a umidade relativa do ar e esse valor varia em função da espécie e das condições climáticas onde ocorre.

$\mathrm{O}$ alto grau de umidade inicial verificado no início da safra, quando grande parte da amostra tinha frutos verdes, indica mais água nos processos iniciais de maturação (Martins \& Silva, 1997), quando os tecidos necessitam de mais umidade para completar seu desenvolvimento; seu posterior e gradual decréscimo (no meio da safra) indica que o maior percentual de frutos da amostra encontra-se maduro, apto a ser colhido. As amostras correspondentes ao meio das safras de 1995 e de 1996 apresentaram, ambas, grande quantidade de frutos verde-amarelados, fase esta que dominou quase todas as colheitas ao longo dos dois anos. Pode-se afirmar, portanto, que apesar da coloração esverdeada, os frutos encontram-se maduros e as sementes aptas a germinar. 


\section{Forrageamento e dispersão}

Levey (1990) demonstra como Miconia centrosema, uma espécie de sub-bosque, se beneficia das condições ambientais proporcionadas pela clareira para aumentar a sua produção de frutos e conseqüentemente a taxa de consumo por frugívoros. É grande ainda a participação das melastomatáceas nos bancos de sementes nas florestas da Guiana, segundo Krijger et al. (1997) devido ao hábito alimentar e a corte dos "manakins" (Pipridae), concentrando grandes quantidades de sementes em suas "arenas" de acasalamento.Os frutos de Miconia cinnamomifolia são dispersos tanto autocorica como zoocoricamente ao longo da safra, e tanto frutos maduros, negros e verde-azulados quanto verdes muito pequenos e os verde-amarelados são encontrados sob as copas, sobre e entre as camadas de serrapilheira.
Representantes da avifauna local consomem grandes quantidades de frutos ao longo da safra, assim como formigas cortadeiras do gênero Atta sp. No entanto, a síndrome de dispersão mais frequente é a barocoria (autocoria) ou em associação com a zoocoria. A título de ilustração, encontram-se listadas na Tabela 3 as aves encontradas na Reserva Biológica de Poço das Antas, no período de 1995-1997 alimentandose de frutos de jacatião.

A mirmecocoria também pode estar associada a dispersão da espécie, embora não seja objetivo precípuo deste a confirmação. Foram observadas formigas cortadeiras (Atta $\mathrm{sp}$ ), nos ramos superiores da copa retirando indiscriminadamente frutos verdes, inclusive ramos da infrutescência, frutos verde-azulados e frutos negros. Formigas foram também observadas entrando com frutos para o interior do formigueiro.

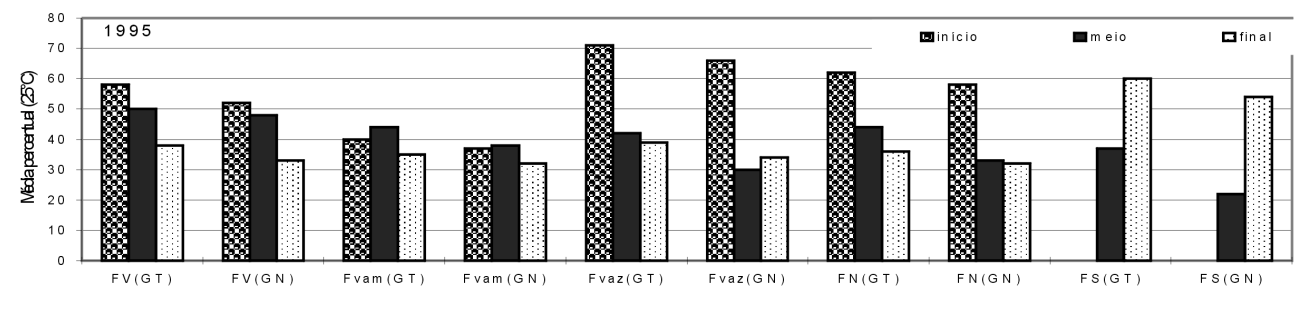

Fases do fruto

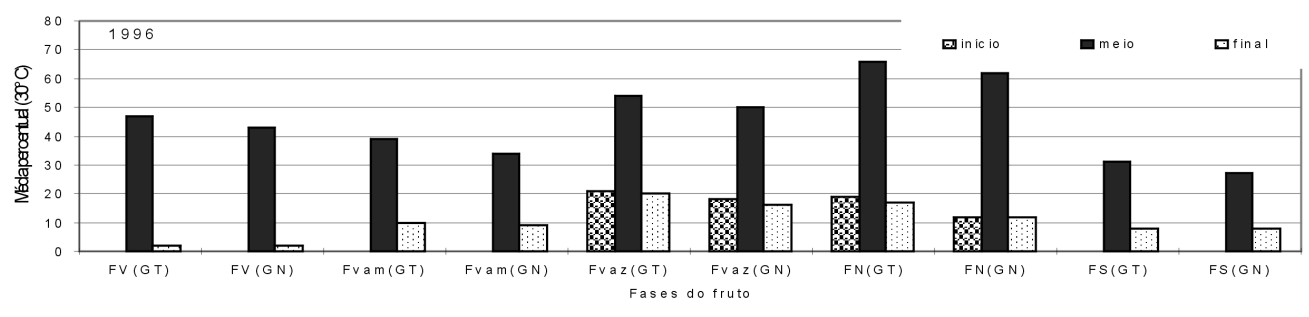

Figura 5. Germinação de sementes (GT) e desenvolvimento de plântulas (GN) de Miconia cinnamomifolia (DC.) Naudin nas diversas fases de amadurecimento em relação ao início, meio e final das safras de 1995 e 1996. ( FN: frutos negros, FS: frutos secos, FV: frutos verdes, FVAM: frutos verde-amarelados, FVAZ: frutos verde-azulados , GT: germinação total, emergência da radícula; GN: germinação normal, desenvolvimento a até plântula final) 
Tabela 3. Ornitofauna associada à frutificação do jacatirão - Miconia cinnamomifolila (DC.) Naud. na Reserva Biológica de Poço das Antas, RJ

\begin{tabular}{|c|c|c|}
\hline FAMÍLIA & NOME CIENTÍFICO & NOME VULGAR \\
\hline \multirow[t]{3}{*}{ Pipridae } & Machaeropterus regulus (Hahn)1819 & Tangará-rajado \\
\hline & Pipra pipra (Linnaeus) 1758 & Cabeça-branca \\
\hline & Pipra rubrocapilla Temminck 1821 & Cabeça-encarnada \\
\hline \multirow[t]{3}{*}{ Tyrannidae } & Capsiemps flaveola (Lichtenstein) 1823 & Marianainha-amarela \\
\hline & Cnemotriccus fuscatus (Wied)1831 & Guaracavuçu \\
\hline & Megarynchus pitangua (Linnaeus) 1766 & Bem-te-vi-de-bico-chato \\
\hline Turdidae & Turdus amaurochalinus Cabanis 1851 & Sabiapoca \\
\hline Vireonidae & Vireo olivaceus (Linnaeus) 1766 & Juruviara \\
\hline Icteridae & Cacicus haemorrhous (Linnaeus)1766 & Guaxe \\
\hline Coerebidae & Conirostrum speciosum (Temminck)1824 & Figurinha-de-rabo-castanho \\
\hline \multirow[t]{3}{*}{ Thraupidae } & Ramphocelus bresilius (Linnaeus)1766 & Tiê-Sangue \\
\hline & Tachyphonus cristatus (Linnaeus) 1766 & Tie-galo \\
\hline & Tangara mexicana (Linnaeus) 1766 & Coleiro-de-banho \\
\hline Fringillidae & Saltator maximus (P.L.S. Muller)1776 & Tempera-viola \\
\hline
\end{tabular}

Nomes científicos e vulgares segundo Sick, 1997

Embora citando o pequeno efeito da dispersão executada por este gênero de formigas, Pijl (1972) explica que todo material é consumido após fermentação; se o interesse está na polpa dos frutos fermentada, as sementes de $M$. cinnamomifolia podem permanecer intactas e viáveis, no interior do formigueiro, incorporadas assim ao banco de sementes.

Kaspari (1993) registrou uma associação do tipo mutualismo para uma guilda de 22 espécies de formigas, onde os frutos de Miconia affinis eram encontrados em diversas profundidades na serapilheira da floresta. As interações entre as formigas e as sementes após a dispersão das mesmas por vertebrados podem ter uma influência importante no sucesso da dispersão das plantas. De acordo com Byrne \& Levey (1993), dois tipos de interações são mais óbvias, a mirmecocoria ou dispersão de sementes ou a predação. As sementes de espécies dispersas por formigas caracterizam-se pela presença de um apêndice carnoso, rico em substâncias lipídicas, que atrai as formigas. Tal apêndice é consumido pelas formigas em seus formigueiros, que descartam as sementes viáveis a sua sorte.
Byrne \& Levey (1993) constataram a presença de apêndices em sementes de algumas melastomataceas, incluindo Miconia nervosa, M. affinis e $M$. centrodesma, retiradas por formigas do gênero Pheidole de fezes de Manacus candei. Segundo os autores é um hábito comum destas formigas o consumo das sementes, podendo ser encarado como predação, no entanto, ao depositarem pilhas de sementes e abandonarem seus formigueiros caracteriza-se a dispersão de fato, pois tais sementes, integram a composição do banco de sementes.

De acordo com Fleming et al. (1993) os frutos dispersos por pássaros geralmente diferem daqueles dispersos por mamíferos por serem pequenos, vermelhos, pretos ou arroxeados, isentos de odores e apêndices de proteção, ricos em lipídeos e proteínas. De acordo com o autor, as características dos frutos associados com as diferentes síndromes de dispersão, presumivelmente refletem diferenças quantitativas bem como qualitativas na morfologia, fisiologia e hábito do dispersor vertebrado potencial. No entanto, dentre os primatas ocorrentes na Reserva, Leontopithecus rosalia rosalia - o 
mico leão dourado é um dos consumidores mais vorazes dos frutos negros de jacatião (obs.pess.).

A medida que os consumidores acessam a copa, e provocam a queda de grandes quantidades de frutos, principalmente os frutos negros, que são de fácil abscisão, sobre a manta florestal, estão colaborando para acelerar a distribuição das sementes. Tal fato estaria relacionado à dispersão do tipo autocórica (ou barocórica). Pijl (1972), entretanto, contesta o termo e a inclusão de algumas espécies por outros autores como barocóricas, afirmando que a maioria se apresenta como oferta a dispersores vertebrados e não como realmente dispersos pela ação do seu peso.

As espécies dos passáros observados se alimentando de frutos de Miconia cinnamomifolia (Tabela 3) na Reserva Biológica de Poço das Antas representam potenciais dispersores da espécie. Diversos estudos na América tropical mencionam a dispersão por frugívoros das melastomataceas. Loiselle \& Blake (1993) associam a distribuição de melastomataceas arbustivas aos hábitos de forrageamento de várias espécies de pássaros na Costa Rica. Stiles \& Rosselli (1993) registram o consumo de Miconia centrosema e $M$. aff. smaragdina, além de outras espécies por pássaros na Costa Rica, Colômbia e Trinidad, sugerindo uma forte associação ecológica entre alguns grupos de pássaros e as melastomataceas.

O tempo de duração da safra, associado à heterogeneidade de fases de amadurecimento dos frutos, e a sua abundância nas copas, conferem uma característica peculiar à Miconia cinnamomifolia na região de sua ocorrência. A predação é minimizada, quando avaliada a oferta. Figliolia (1993), estudando a maturação de sementes de Inga uruguensis , constatou que quando o período de maturação dos frutos foi mais prolongado, a taxa de predação foi maior. Tal resultado levou a autora a afirmar que quanto maior o período que os frutos e sementes permanecem no campo, em processo de amadurecimento, mais expostos estão aos agentes predadores. Por outro lado, na visão de Peres (1994) em seu estudo sobre palmeiras da amazônia, os frutos maduros persistem intactos por muitas semanas, seja no chão ou mesmo na infrutescência, constituindo assim um recurso alimentar para a fauna, por muitos meses ao ano. Esta parece ser também uma das formas de oferta utilizadas pelo jacatirão, pois as safras subsequentes permitem que haja, por um longo prazo (6-7 meses), recursos disponíveis à fauna.

As observações sobre a espécie em estudo e a literatura sobre a interação planta-animal em outros grupos, auxiliam a levantar evidências que indicam o consumo de frutos de jacatirão pela fauna presente na Reserva, e, fornecem subsídios para estudos mais profundos sobre os dispersores da espécie na mata atlântica.

\section{Agradecimentos}

Este trabalho foi realizado com auxílio do $\mathrm{CNPq}$ e do Programa Mata Atlântica do Instituto de Pesquisas do Jardim Botânico do Rio de Janeiro. Os autores são gratos à Dr. Fábio Rubio Scarano e a Dr. José Fernando de A. Baumgratz e aos revisores anônimos pelos comentários que muito enriqueceram o trabalho. Eainda aos auxiliares de campo Antônio Tavares, Adilson Pintor e a Cintia Luchiari pelo auxílio no trabalho de campo e a Ana Paula Martins Cruz pelo trabalho no Laboratório de Sementes. A tabela com a relação dos pássaros que visitam o Jacatirão teve a colaboração da MSc Jozélia Correia de Souza a quem os autores agradecem.

\section{Referências bibliográficas}

Barnett, J.P. 1979. Maturation of tree seeds. pp.206-17. In: Symposium on flowering and seed development in trees, Starkville. Proceedings. US Forest Service. Borges, E.E.L. \& Borges, C.G. 1979. Germinação de sementes de Copaifera langsdorfii Desf. provenientes de frutos com difrentes graus de maturação. Revista Brasileira de Sementes 1(3): 45-47.

BRASIL. Ministério da Agricultura e Reforma Agrária. 1992. Regras para análise de sementes. Brasília, SNDA/DNDV/CLAV. 365p.

Byrne, M.M. \& Levey, D.J. 1993. Removal of seeds from frugivore defecations by ants in a Costa Rican rain forest. In: Fleming, T.H. \& Estrada, A. (eds.). Frugivory and seed dispersal: Ecological and evolucionary aspects. Vegetatio 107/108: 363-374.

Carvalho, N.M. \& Nakagawa, J. 1980. Sementes. Ciência, tecnologia e produção. Campinas, Fundação 
Cargill. 326p.

Fenner, M. 1985. Seed ecology. London. Chapmam \& Hall. 151p.

Figliolia, M.B. 1993. Maturação de sementes de Inga uruguensis Hook. et Arn. associada a fenologia reprodutiva e a dispersão de sementes em floresta ripária do rio Moji Guaçu, Município de Moji Guaçu SP. ESALQ-USP. (Dissertação de Mestrado)

Fleming, T.H., Venable, D.L. \& Herrera M., L.G. 1993. Opportunism vs. speciation: the evolution of dispersal strategies in fleshy-fruited plants. In: Fleming, T.H. \& Estrada, A. (eds.). Frugivory and seed dispersal: Ecological and evolucionary aspects. Vegetatio 107/108: 107-120.

Janzen, D. H. 1967. Synchronization of sexual reproduction of trees within the dry season in Central America. Evolution 21:620-27.

Kaspari, M 1993. Removal of seeds from Neotropical frugivore droppings. Oecologia 95: 81-88.

Krijger, C.L, Opdam, M., Théry, M. \& Bongers, F. 1997. Courtship behaviour of manakins and seed bank composition in a French Guianan rain forest. Journal of Tropical Ecology 13: 631-636.

Lee, T.D. 1990. Patterns of fruit and seed production. pp 179-209. In: Lovett Doust, J. \& Lovett Doust, L. (eds). Plant reproductive ecology - Patterns and strategies. Oxford Univ. Press, Oxford.

Levey, D.J. 1990. Habitat-dependent fruiting behavior of an understorey tree, Miconia centrodesma, and tropical treefall gaps as keystone habitats for frugivores in Costa Rica. Journal of Tropical Ecology 6: 409-420.

Loiselle, B.A. \& Blake, J.G. 1993. Spatial distribution of understory fruit-eating birds and fruiting plants in a neotropical lowland wet forest. In: Fleming, T.H. \& Estrada, A. (eds.). Frugivory and seed dispersal: Ecological and evolucionary aspects. Vegetatio 107/ 108:177-189.

Marcos Filho, J. 1979. Qualidade fisiológica $\boldsymbol{e}$ maturação de sementes de soja Glycine max (L.) Merrill. Piracicaba, ESALQ-USP. 180p. (Tese de Livre-Docência).

Martinez-Ramos \& Soto-Castro, A. 1993. Seed rain and advanced regeneration in a tropical rain forest. In: Fleming, T.H. \& Estrada, A. (eds.). Frugivory and seed dispersal: Ecological and evolucionary aspects. Vegetatio 107/108: 299-318.

Martins, S.V. \& Silva, D.D. 1997. Maturação e época de colheita de sementes de Dalbergia nigra (Vell.) Fr.All. ex Benth. Revista Brasileira de Sementes. 19(1): 96-99.

Peres, C. A. 1994. Composition, density and fruiting phenology of arborescent palms in Amazonian Terra Firme forest. Biotropica 26(3): 285-294.

Pijl, L. van der. 1972. Principles of dispersal in higher plants. 2ed. Berlin. Springer-Verlag. 161p.

Popinigis, F. 1985. Fisiologia da semente. Brasília, AGIPLAN, 289p.

Queiroz, M.H. 1983. Influência da luz na germinação de Miconia cinnamomifolia (De Candolle) Naudin - Jacatião-açu. Ínsula 13:29-37.

Randi, A.M. 1982. Estudo preliminar sobre inibidores de germinação em frutos de Miconia cinnamomifolia e Ocotea puberula. An. Congr. Nac. Essências Nativas, Silvicultura 16(1):238-242.

Sick, H. 1997. Ornitologia Brasileira. Ed. Nova Fronteira, RJ. 912p.

Snow, D. H. 1981 . Tropical frugivorous birds and their food plants: a world survey. Biotropica 13(2): 1314.

Stiles, F.G \& Rosselli, L. 1993. Consumption of fruits of the Melastomataceae by birds: how diffuse is coevolution? In: Fleming, T.H. \& Estrada, A. (eds.). Frugivory and seed dispersal: Ecological and evolucionary aspects. Vegetatio 107/108: 57-73. 